\title{
Bruno Kyewski 1950-2018
}

B runo Kyewski passed away on 22 March 2018. In the midst of dismay and grief for the loss of a mentor and companion in many scientific endeavors, it is comforting to know that Bruno had his wonderful wife Jacky and his son Felix close by his side through the difficult times since he was diagnosed with disseminated prostate cancer in the fall of 2015.

Bruno studied medicine in Bonn and Zurich and obtained his MD degree from the University of Freiburg. After postdoctoral training with Hartmut Wekerle in Freiburg and with Henry Kaplan in Stanford, he became a principal investigator and later head of the Division of Developmental Immunology at the German Cancer Research Center in Heidelberg. Early on, Bruno was fascinated by the idea of taking the thymus to pieces to delineate the functional properties of its stromal compartments. In the late 1970 s, this was a daunting task. Bruno rose to the challenge by meticulously perfecting several (by today's standards archaic) cell-separation methods such as ' 1 - $g$-sedimentation'. His record yields were never matched in the years to come. Indeed, it was the combination of his brilliant and creative mind and supreme dexterity in the ex vivo preparation of rare cells that enabled Bruno to reveal fundamental aspects of thymus biology. As a postdoctoral fellow, Bruno showed that thymic dendritic cells were exquisitely efficient in presenting circulating self antigens, whereas cortical thymic epithelial cells, despite their equally abundant expression of major histocompatibility complex (MHC) class II, failed to do so. More than a decade before the discovery of unique antigen-processing machineries in cortical thymic epithelial cells essential for positive selection, Bruno's seminal observation already suggested fundamental differences in the way peptideMHC ligands are generated for central tolerance on the one hand and positive selection on the other.

After establishing his own laboratory in 1984, Bruno studied the half-life of peptideMHC class II complexes in various organ microenvironments. The kinetic aspects of antigen presentation received little attention at the time, and the concept of dendritic cell maturation was only beginning to emerge. Bruno observed a considerably longer half-life of peptide-MHC complexes in the thymus than in peripheral organs, which had obvious implications for the induction of

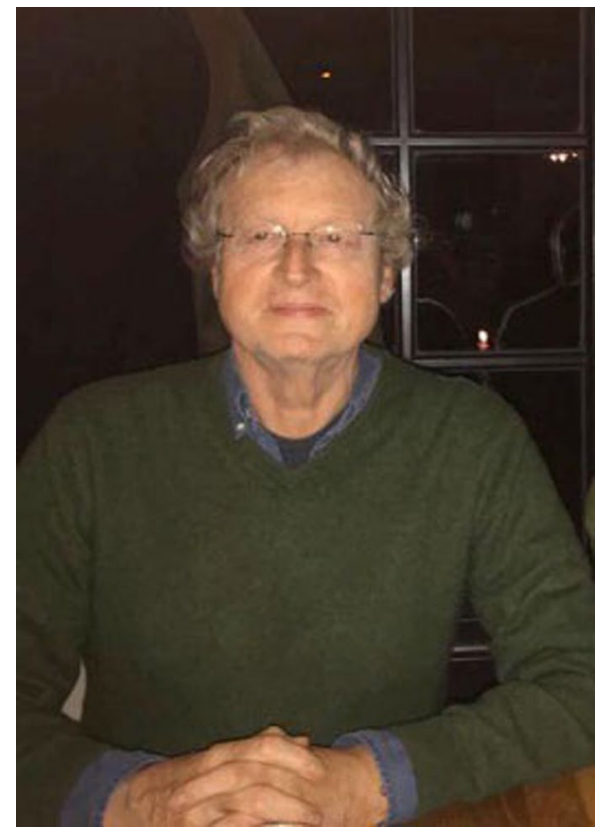

to ectopic intrathymic expression of our transgenic neo-antigen, yet Bruno, following his remarkable scientific instincts, insisted that we pursue this unexpected finding further. It turned out that intrathymic expression indeed was a physiological feature not only of acutephase proteins but also essentially of every TRA we examined. We coined the term 'promiscuous gene expression', and Bruno's knack for stromal cell separation once again was instrumental in showing that this phenomenon is a unique feature of medullary thymic epithelial cells. After that fundamental discovery, Bruno continually provided insights into the molecular regulation of promiscuous gene expression and how it supports tolerance induction. His finding that medullary thymic epithelial cells can hand over TRAs to dendritic cells suggested an elegant mechanism by which self antigens that are expressed by only a few hundred cells per thymus can nonetheless efficiently promote central tolerance. Bruno's work shed light on the extent and inter-individual variation of promiscuous gene expression in the human thymus, suggesting that variability in thymic autoantigen expression might constitute a hitherto unappreciated risk factor for autoimmune diseases. Indeed, Bruno and others reported that allele-specific variations in intrathymic expression correlate with disease susceptibility in type 1 diabetes, myasthenia gravis, Grave's disease and autoimmune myocarditis.

Those who had the privilege of getting to know Bruno will remember him as a warmhearted, unassuming and openminded person. Every so often, he seemed fallen out of time in the most positive sense, enormously knowledgeable and literate far beyond research, driven by genuine curiosity and an enviable ability to marvel at things. Bruno would never be seen blatantly 'selling' a story, and he was always extremely critical with his own work, being the first to point out potential caveats. Writing these lines, I can see Bruno, raising his eyebrows while asking: "Was it all that important?" Sure it was, Bruno; we will sorely miss you.

\section{Ludger Klein \\ Institute for Immunology, Ludwig-Maximilians- \\ University, Munich, Germany. \\ e-mail:ludger.klein@med.uni-muenchen.de}

Published online: 11 April 2018

https://doi.org/10.1038/s41590-018-0095-1 